\title{
ACTIVIDAD DEL TRIBUNAL CONSTITUCIONAL: RELACIÓN DE SENTENCIAS DICTADAS DURANTE EL PRIMER CUATRIMESTRE DE 2021
}

\section{Activity of the Constitutional Court: List of rulings handed down during the third four-month period of 2021}

\author{
ÁREA DE DERECHO CONSTITUCIONAL \\ Universidad Carlos III de Madrid' \\ aelvira@der-pu.uc3m.es
}

Cómo citar/Citation

Elvira Perales, A. y Espinosa Díaz, A. (coords.) (2021).

Actividad del Tribunal Constitucional: relación de sentencias dictadas

durante el primer cuatrimestre de 2021

Revista Española de Derecho Constitucional, 122, 217-246.

doi: https://doi.org/10.18042/cepc/redc.122.07

Durante el primer cuatrimestre de 2021 se han dictado las sentencias que se reseñan a continuación: ocho.

A) Las sentencias dictadas en recursos de inconstitucionalidad han sido

La Sentencia (en adelante STC) 13/2021, de 28 de enero, resuelve el recurso interpuesto por el Parlamento de Cataluña en relación con los arts. $20 ; 35.1 ; 36.1,2,8,22$ y 23, y 37.7, así como la disposición final primera de la Ley Orgánica 4/2015, de 30 de marzo, de protección de la seguridad ciudadana. En ella, en primer lugar, se recuerda que algunos de los preceptos recurridos ya fueron objeto de la STC 172/2020, remitiendo a ella en aquellos

1 La presente relación de sentencias ha sido elaborada por los profesores Elvira Perales y Espinosa Díaz (coords.), Gómez Lugo, Baamonde Gómez y López Rubio. 
aspectos en los que existe concomitancia. En particular, destaca, con respecto a la impugnación del art. 20, que, dado que se indica que el registro corporal se utilice solo cuando "existan indicios racionales», «sujeta la decisión de practicarlo a un parámetro de razonabilidad objetiva verificable en cada caso concreto y convierte esa medida de intervención en suficientemente previsible»; en relación con el art. 35.1 especifica, a su vez, que, «junto al criterio geográfico de contigüidad o gran cercanía, debe acontecer el riesgo para los bienes jurídicos indicados», por lo que, si bien existe un margen de apreciación, excluye una decisión prácticamente libre de los órganos administrativos o judiciales.

Por su parte, al analizar la impugnación del art. 36.1 afirma que su contenido no resulta indeterminado incumpliendo la garantía del art. 25.1 CE si se interpreta en conexión con otros preceptos de la propia LOSC o los arts. 557 y $558 \mathrm{CP}$, a la vez que recuerda el amplio margen de que dispone el legislador para regular el régimen sancionador, siempre que no suponga una extralimitación; mientras que, en relación con el art. 36.2, manifiesta que en este contexto legal "la expresión "frente a las sedes" es un término equivalente a "enfrente de" o "delante de" y dada la finalidad de la norma, la manifestación ha de estar próxima a los edificios, pues, sin esa proximidad, no parece que se pueda impedir el normal funcionamiento del órgano o llevar a cabo la desconsideración del símbolo que encarnan las sedes». Igualmente desestima la impugnación del art. 36.8 al considerar que «es un concepto jurídico indeterminado cuya concreción es razonablemente previsible en virtud de criterios lógicos, técnicos o de experiencia», y, de forma parecida, declara con respecto al art. 36.22 «el bien jurídico protegido y describe suficientemente en qué consiste la conducta punible».

A la luz de lo anterior, la sentencia falla lo siguiente:

1. ${ }^{\circ}$ Desestimar la pretensión de inadmisión de la impugnación dirigida contra la disposición final primera de la Ley Orgánica 4/2015, de 30 de marzo, de protección de la seguridad ciudadana.

2. Declarar la pérdida de objeto del presente recurso de inconstitucionalidad en lo que hace a la impugnación del inciso «no autorizado» del art. 36.23 LOPSC.

3. ${ }^{\circ}$ Declarar que los arts. 36.23 y 37.7 LOPSC no son inconstitucionales siempre que se interpreten en el sentido establecido en el FJ 2.c el art. 36.23 y en el FJ 2.d el art. 37.7.

$4 .^{\circ}$ Declarar que la disposición final primera por la que se introduce la disposición adicional décima en la Ley Orgánica 4/2000, de 11 de enero, sobre derechos y libertades de los extranjeros en España y su 
integración social, es conforme a la Constitución, siempre que se interprete tal y como se ha indicado en el FJ 2.e.

$5 .^{\circ}$ Declarar que el art. 36.22 LOPSC no es inconstitucional siempre que se interprete que la conducta que tipifica consiste en (i) el incumplimiento de las restricciones a la navegación en esos sectores impuestas por motivos de seguridad ciudadana (ii) que produjese como resultado un perjuicio real para la seguridad ciudadana o una amenaza concreta de la que razonablemente se pueda seguir aquel perjuicio.

6. ${ }^{\circ}$ Desestimar el recurso de inconstitucionalidad en todo lo demás.

Formulan sendos votos particulares discrepantes el Sr. Conde-Pumpido y la Sra. Balaguer, en línea con los que formularon a la STC 172/2020.

La STC 16/2021, de 28 de enero, resuelve el recurso interpuesto por más de cincuenta diputados del Grupo Parlamentario Popular del Congreso respecto de los decretos leyes del Gobierno de la Generalitat de Cataluńa 17/2019, de 23 de diciembre, de medidas urgentes para mejorar el acceso a la vivienda, y 1/2020, de 21 de enero, por el que se modifica el anterior, y el acuerdo del Parlamento Cataluña de convalidación del Decreto Ley 1/2020. Las tachas de inconstitucionalidad respecto del primer decreto ley recurrido se basan en la eventual falta de presupuesto habilitante, y subsidiariamente se impugnan varios de sus artículos por motivos tanto competenciales como sustantivos. Por cuanto a la segunda norma objeto de juicio de inconstitucionalidad, el recurso, en los motivos que dirige contra el art. 2.1 del Decreto Ley 17/2019, o que toman como premisa la definición de «vivienda vacía» establecida en el mismo precepto, se dirige también expresamente contra el artículo único del Decreto Ley 1/2020 y la modificación efectuada en este. En tercer lugar, el cuestionamiento del acuerdo de validación se funda en que fue emitido expirado el plazo de 30 días desde la promulgación de la norma provisional que exige el art. 64.2 del Estatuto de Autonomía de Cataluña. El Tribunal comienza su razonamiento jurídico por esta tercera impugnación, llegando a la conclusión de que el término "promulgación» referido a los decretos leyes no es homologable al concepto en relación con las leyes parlamentarias (promulgación regia). Así, esta promulgación de las normas gubernamentales debe asociarse al acto de publicación, y, por lo tanto, el acuerdo de validación habría sido adoptado en plazo.

En lo que respecta a la concurrencia o no del presupuesto habilitante para la adopción del decreto ley, el Tribunal, en su rol del control jurídico externo, considera que la exposición de motivos cumple con los requisitos exigidos por su reiterada doctrina acerca de la interpretación de la «extraordinaria y urgente necesidad», a lo que deben añadirse los datos aportados en el 
debate de convalidación por parte el consejero de Territorio y Sostenibilidad. En cuanto a la alegación de falta de "conexión de sentido de las medidas» previstas, el Pleno aclara que no debe confundirse eficacia inmediata de la norma provisional con ejecución instantánea de esta, pues esta segunda estará condicionada por la naturaleza y complejidad de la propia medida adoptada.

Por lo que se refiere a la vulneración de la reserva material del decreto ley por afectar al derecho fundamental a la propiedad privada (art. $33 \mathrm{CE}$ ), se acude a la jurisprudencia previa en la materia para recordar la importancia de una interpretación restrictiva del término «afectación». Así, proyectando la precedente doctrina sobre los preceptos impugnados en esta parte del recurso, el Tribunal comprueba que estos exceden del marco permitido a los decretos leyes por la previa STC 93/2015. Los artículos objeto de impugnación por este motivo, con algunas excepciones, van más allá de «delimitar un concreto sistema urbanístico o una determinada política de vivienda», "disciplinar un sector material en el que dicho derecho constitucional [el de propiedad] pueda incidir», o de «ceñirse a precisar los usos posibles de las edificaciones según el lugar en que se ubiquen dentro de la ciudad o a disciplinar el sector de la vivienda», como permitía la STC 93/2015, y se encaminan más bien a establecer «el único uso posible de un determinado tipo de bienes» mediante una «regulación directa y con vocación de generalidad de las vertientes individual e institucional del derecho de propiedad sobre la vivienda» que «se dirige a precisar el haz de facultades que integra este tipo de derecho de propiedad privada y, al mismo tiempo, a definir la función social del mismo», en consecuencia, van más allá de la regulación de las «medidas de fomento» que contenía el Decreto Ley de la Junta de Andalucía 6/2013 impugnado en su momento. Se descartan, sin embargo, las consideraciones de tipo competencial, así como las hipotéticas vulneraciones de los derechos a la intimidad o al tratamiento automatizado de datos personales (art. $18 \mathrm{CE}$ ) por la creación de un registro de viviendas vacías por parte de la Generalitat.

Concluye así el Tribunal declarando inconstitucionales y nulos los arts. 2.2 , 2.3, 2.4, 2.5, 2.7, 2.10, 2.11 (inciso «sin perjuicio del supuesto a que hace referencia el artículo 42.6»), 2.12, 4.2, 4.5 (inciso «y del apartado 2 de la disposición adicional primera»), 5.5, 5.6, 5.7, 6.3 y 6.6 y la disposición transitoria primera del Decreto Ley del Gobierno de la Generalitat de Cataluña 17/2019, de 23 de diciembre, de medidas urgentes para mejorar el acceso a la vivienda. Y desestimando las demás impugnaciones formuladas.

La STC 38/2021, de 18 de febrero, resuelve el recurso interpuesto por el presidente del Gobierno respecto del apdo. segundo de la disposición transitoria décima de la Ley del Parlamento Vasco 7/2019, de 27 de junio, de quinta modificación de la Ley de policía del País Vasco. Se denuncia que dicho 
apartado vulnera el orden constitucional de distribución de competencias al establecer un turno diferenciado de acceso a la función pública para quienes acrediten un mínimo de ocho ańos de antigüedad en la Administración convocante en la categoría de la policía local a la que pertenecen las plazas convocadas, contraviniendo la norma básica estatal dictada al amparo del art. 149.1.18 CE. Así, la articulación de unas pruebas de acceso que tienen carácter restringido quebrantaría la garantía del cumplimiento de los principios de igualdad, mérito, capacidad y publicidad exigidos en la disposición transitoria cuarta del Real Decreto Legislativo 5/2015, de 30 de octubre, por el que se aprueba el texto refundido de la Ley del estatuto básico del empleado público. Además, la competencia autonómica en materia de régimen estatutario de sus funcionarios públicos puede encontrar en el art. 149.1.13 CE un límite en el ejercicio legítimo de la mencionada competencia estatal para establecer las bases de la planificación económica general. Antes de entrar en el fondo de la cuestión, el Tribunal se plantea si concurre una situación de pérdida sobrevenida de objeto por la derogación expresa de la norma impugnada, al ser sustituida por el posterior Decreto Legislativo 1/2020, de 22 de julio. Tal pérdida no procede en la medida en que la nueva norma reproduce literalmente la previsión objeto de litigio, de modo que una eventual inconstitucionalidad debería hacerse extensible al apdo. segundo de la disposición transitoria novena de esta. Para abordar el fondo de la cuestión controvertida, el método que aplica el Tribunal es el del encuadre competencial y el de la eventual inconstitucionalidad mediata, que requiere determinar el carácter básico o no de la legislación estatal, para posteriormente analizar la ulterior contradicción. Sentado que al Estado le corresponde el establecimiento de las bases del régimen estatutario de los funcionarios de todas las Administraciones públicas (art. 149.1.18 CE) y a la comunidad autónoma del País Vasco, el desarrollo legislativo y la ejecución de las bases de dicho régimen estatutario en lo que se refiere a los funcionarios al servicio de la comunidad autónoma y al servicio de las corporaciones locales radicadas en su ámbito territorial (art. 10.4 EAPV), la legislación estatal en la materia es, por tanto, básica, y del contraste entre ambas normas se desprende una contradicción no salvable mediante interpretación conforme a la Constitución; el Tribunal declara la inconstitucionalidad y nulidad del precepto, haciendo los efectos extensibles al apdo. segundo de la disposición transitoria novena del Decreto Legislativo del Parlamento Vasco 1/2020, de 22 de julio, por el que se aprueba el texto refundido de la Ley de policía del País Vasco que reproduce el precepto legal declarado inconstitucional.

La STC 40/2021, de 18 de febrero, resuelve y desestima el recurso interpuesto por más de cincuenta senadores del Grupo Parlamentario Socialista 
respecto del Decreto Ley de la Junta de Castilla y León 6/2020, de 2 de julio, de medidas urgentes para incentivar las medidas de recuperación económica y social en el ámbito local. El decreto ley impugnado tiene un artículo único, con cinco apartados, por los que se modifican determinados aspectos de la Ley 10/2014, de 22 de diciembre, de medidas tributarias y de financiación de las entidades locales vinculada a los ingresos impositivos de la Comunidad de Castilla y León. Las modificaciones sustantivas se encuentran en los apdos. cuatro y cinco, dedicados, respectivamente, al «Fondo de participación en los impuestos propios de la Comunidad de Castilla y León» y al «Fondo de cooperación económica local general». En primer lugar, en cuanto al presupuesto habilitante para la aprobación de la norma provisional, el Tribunal concluye que en el preámbulo y en la memoria del decreto ley, así como en su presentación en el trámite parlamentario de convalidación, la Junta de Castilla y León ha ofrecido, de forma explícita y razonada, una justificación para la adopción de las medidas aprobadas. Igualmente aprecia la urgencia de la intervención y la imprevisibilidad de la situación (crisis económica generada por la pandemia de la covid-19) y descarta el carácter estructural de las previsiones impugnadas. En relación con la queja de la "conexión de sentido» de la norma gubernamental con la situación de "extraordinaria y urgente necesidad», admitiendo la discrecionalidad de que goza el Ejecutivo autonómico y procediendo en consecuencia a un juicio de razonabilidad, sostiene que aquella es suficiente y admite que las inversiones se vinculen a los Objetivos de Desarrollo Sostenible de la Agenda 2030. Finalmente concluye con la desestimación total del recurso al rechazar la tercera tacha de inconstitucionalidad, por entender que la modificación que introduce el Decreto Ley 6/2020 en las reglas de condicionalidad, al no referirse al Fondo de participación sino únicamente al de cooperación, no incumple el límite material fijado por el art. 25.4, en conexión con el art. 55.3 EACL.

La STC 68/2021, de 18 de marzo, resuelve el recurso interpuesto por el Gobierno de Aragón en relación con diversos preceptos de la Ley 9/2017, de 8 de noviembre, de contratos del sector público, por la que se transponen al ordenamiento jurídico español las directivas del Parlamento Europeo y del Consejo 2014/23/UE y 2014/24/UE, de 26 de febrero de 2014. El Tribunal, tras hacer un breve excurso acerca de la finalidad de ley estatal, más allá de la mera transposición de la normativa europea de referencia, y, una vez delimitado el objeto del recurso al hilo de las modificaciones normativas efectuadas con posterioridad a su interposición, procede al examen pormenorizado de las alegaciones por el siguiente orden: i) las quejas suscitadas en relación con la vulneración del principio de neutralidad en la trasposición del derecho europeo; ii) el no reconocimiento del carácter foral de la comunidad 
autónoma de Aragón; iii) los motivos de inconstitucionalidad que se alegan por vulneración del orden competencial constitucional y estatutariamente establecido en materia de contratación pública, conforme a lo dispuesto en el art. 149.1.18 CE, que atribuye al Estado la legislación básica en la materia, y a los arts. 75.11 y 12 del Estatuto de Autonomía de Aragón, que otorgan a la comunidad autónoma competencia de desarrollo legislativo y ejecución; iv) la constitucionalidad de los arts. 41.3, 44.6 y 128 LCSP, a los efectos de determinar si se trata de normas de carácter supletorio. Así, tras fijar la controversia dentro de los márgenes del derecho interno y negar a la comunidad de Aragón la condición «territorio histórico» a los efectos de la disposición adicional primera $\mathrm{CE}$, resuelve la controversia competencial (partiendo de qué debe entenderse por legislación básica en materia de contratación) concluyendo con una estimación parcial y precisiones interpretativas que llevan a dividir el fallo en cuatro bloques, desestimando el resto de consideraciones del recurso:

$1 .^{\circ}$ Declara el Tribunal inconstitucionales y nulos los siguientes preceptos de la Ley 9/2017, de 8 de noviembre, de contratos del sector público: el párrafo segundo del art. 46.4, el inciso «que serán eficaces, únicamente, a efectos de contratar con la comunidad autónoma que las haya adoptado, con las entidades locales incluidas en su ámbito territorial, y con los entes, organismos y entidades del sector público dependientes de una y otras» del art. 80.2 y el inciso «de forma exclusiva y excluyente» del párrafo 5 del art. 347.3. La parte subsistente de ambos preceptos ha de interpretarse conforme a lo expresado, respectivamente, en el FJ 6.G.f y en el FJ 8.D.

2..$^{\circ}$ Declara que no son conformes con el orden constitucional de competencias los incisos «de diez días», «de dos días hábiles» y "cinco días hábiles» del art. 52.3 (FJ 6.E.c) y el inciso "con una antelación mínima de cinco días» del art. 242.3 de la Ley 9/2017, de 8 de noviembre, de contratos del sector público (FJ 7.C.e).

$3 .{ }^{\circ}$ Declara que son conformes con el orden constitucional de competencias, siempre que se interpreten en los términos establecidos en el fundamento jurídico que se indica en cada caso, los siguientes preceptos de la Ley 9/2017, de 8 de noviembre, de contratos del sector público: art. 41.3 (FJ 9.b); art. 58.2 (FJ 6.E.d); art. 82.2 (FJ 6.G.g); art. 177.3 a) (FJ 7.B.h); art. 187.11 (FJ 7.B.i); la disposición adicional trigésima octava (FJ 8.E), y el párrafo primero del apdo. 3 de la disposición final primera (FJ 10).

4..$^{\circ}$ Declara que no son conformes con el orden constitucional de competencias, con las salvedades y en los términos del fundamento jurídico 
que se indican en cada caso, los siguientes preceptos de la Ley 9/2017, de 8 de noviembre, de contratos del sector público: art. 72.4 (FJ 6.G.c); el párrafo primero del art. 122.2, salvo los incisos relativos a la necesidad de incluir «los pactos y condiciones definidores de los derechos y obligaciones de las partes del contrato» y "En el caso de contratos mixtos, se detallará el régimen jurídico aplicable a sus efectos, cumplimiento y extinción, atendiendo a las normas aplicables a las diferentes prestaciones fusionadas en ellos» (FJ 7.A.d); art. 125.1 (FJ 7.A.e); los párrafos segundo y tercero del art. 154.7 (FJ 7.B.e); los párrafos primero, segundo, tercero, quinto y sexto del art. 185.3 (FJ 7.B.i); el art. 212.8 (FJ 7.C.c), y el apdo. 2 de la disposición final sexta (FJ 8.F).

La STC 72/2021, de 18 de marzo, resuelve el recuro interpuesto por el presidente del Gobierno en relación con diversos preceptos de la Ley 6/2019, de 20 de febrero, del estatuto de las personas consumidoras de Extremadura. Estima parcialmente el recurso interpuesto por el presidente del Gobierno contra los arts. 13 d), 17.2, 28.6 y 29 de la Ley 6/2019, de 20 de febrero, del estatuto de las personas consumidoras de Extremadura. Salvados los óbices procesales señalados por las partes y delimitado el objeto de enjuiciamiento, el Tribunal procede al deslinde competencial señalando que la delimitación entre el Estado y las comunidades autónomas en la materia relativa a la defensa de los consumidores y usuarios no se define de manera expresa en los arts. 148 y $149 \mathrm{CE}$, por lo que debe considerarse, en principio, como una competencia asumible por las comunidades autónomas en sus estatutos de autonomía (como efectivamente ha hecho el Estatuto de Autonomía de Extremadura en su art. 9.1.18). Sin embargo, la asunción como exclusiva de esta competencia por parte de la comunidad autónoma no excluye la capacidad estatal de incidir en la materia, dado que la competencia estatutaria tiene que cohonestarse con aquellos títulos competenciales que puedan afectar a esta y que la Constitución reserva al Estado en el art. 149.1 CE. Sentado esto, se procede a un análisis individualizado de los preceptos objeto de impugnación a fin de determinar si su alcance supone una invasión de competencias estatales. Resuelve que el art. $13 \mathrm{~d}$ ), el primer párrafo del art. 17.2, el inciso «y debe comunicarles que esta cláusula dejará de aplicarse en los términos establecidos por la resolución o sentencia judicial», del art. 28.6, y los arts. 29 y 73.41 (por conexión o consecuencia) de la Ley 6/2019, de 20 de febrero, del estatuto de las personas consumidoras de Extremadura, son inconstitucionales y nulos; desestimando el recurso en todo lo demás.

La STC 74/2021, de 18 de marzo, resuelve el recuro interpuesto por el presidente del Gobierno respecto del art. 19 de la Ley del Parlamento de 
Canarias 6/2019, de 9 de abril, de calidad agroalimentaria. Sostiene la Abogacía del Estado que este artículo incurre en inconstitucionalidad mediata o indirecta, por vulneración de lo dispuesto en el art. 2, apdos. 2 e) y 3 , de la Ley 24/2003, de 10 de julio, de la vińa y del vino, normativa básica dictada por el Estado al amparo de la competencia conferida por el art. 149.1.13 CE, en materia de bases y coordinación de la planificación general de la actividad económica. Así, partiendo de que el Estado dispone de competencia para adoptar la decisión de mantener o modificar la definición de vino y la reserva de denominación contenida en la normativa básica, sin que corresponda al Tribunal examinar la oportunidad o el acierto de la medida legal, resulta claro que el precepto impugnado, al autorizar la denominación de «vino» para la comercialización de productos obtenidos a partir de la fermentación de frutas distintas de la uva, entra en contradicción efectiva e insalvable por vía interpretativa con esas disposiciones básicas, particularmente con el art. 2.3, que establece el carácter excluyente de las definiciones y prohíbe que se utilicen esas denominaciones en productos que no se ajusten estrictamente a la definición recogida en el art. 2.2 e). Consecuentemente se declara la inconstitucionalidad y nulidad del precepto impugnado.

La STC 75/2021, de 18 de marzo, resuelve el recurso interpuesto por más de cincuenta diputados del Grupo Parlamentario Vox en el Congreso de los Diputados respecto del art. 3 bis del Reglamento de la Junta General del Principado de Asturias, en la redacción dada por la reforma de 1 de julio de 2020. El Tribunal comienza subrayando que «la diversidad lingüística es una realidad cuyo respeto constituye un valor fundamental reconocido por la Constitución como patrimonio común y expresión de la diversidad cultural de España». En este sentido, acude a su doctrina constitucional sobre la cooficialidad lingüística (STC 56/2016) y recuerda que «en la configuración del estatuto de las lenguas españolas distintas del castellano la Constitución deja un importante espacio a la regulación por los estatutos y las leyes de las comunidades autónomas». También subraya que, en virtud del art. 3.3 CE, «el constituyente ha demandado tutelar, también, aquellas realidades lingüísticas que no están amparadas por el estatuto de la oficialidad lingüística en un determinado territorio autonómico, para lo cual corresponderá a los poderes públicos disponer las garantías tanto de respeto como de protección de aquellas, lo cual incluye la posible regulación de su uso público bajo determinadas circunstancias». De este modo, concluye que el precepto reglamentario impugnado «no tiene como resultado la atribución de los efectos propios de la oficialidad a una lengua propia, pues no reconoce al bable/asturiano como "medio normal de comunicación" ante todos los poderes públicos radicados en el territorio autonómico, sino únicamente reconoce determinados efectos en el seno 
de la institución parlamentaria autonómica. Es claro que el precepto impugnado no regula dicha cooficialidad", por el contrario, se limita a establecer que la Junta General

[...] acepta la utilización de la lengua asturiana tanto por los diputados en el ejercicio de sus funciones parlamentarias como por los miembros del Consejo de Gobierno, los cargos y empleados públicos o cualquier persona que comparezca ante la Cámara, como medio de asegurar la protección, el uso y la promoción del bable a las que se refiere el art. 4 del Estatuto de Autonomía en desarrollo de lo dispuesto en el apartado 3 del art. 3 CE cuando dispone que «la riqueza de las distintas modalidades lingüísticas de España es un patrimonio cultural que será objeto de especial respeto y protección».

En consecuencia, desestima el recurso de amparo.

La sentencia va acompañada de dos votos particulares formulados por la magistrada Encarnación Roca Trías y el magistrado Pedro José González-Trevijano Sánchez.

B) Las sentencias dictadas en cuestiones de inconstitucionalidad han sido dos.

La STC 14/2021, de 28 de enero, resuelve la cuestión planteada por la Sección Cuarta de la Sala de lo Contencioso-Administrativo del Tribunal Supremo respecto del art. 153.1 de la Ley Orgánica 5/1985, de 19 de junio, del régimen electoral general, en relación con los arts. 53 y 50.4 LOREG. Las normas en cuestión establecen las sanciones que aplicar por incumplimiento de la prohibición de difundir propaganda electoral o realizar actos de campaña electoral una vez que esta haya finalizado legalmente. El Tribunal descarta la existencia de vulneración del mandato de taxatividad de las infracciones y determinación de las sanciones derivado del art. $25 \mathrm{CE}$ por los siguientes motivos: i) la conducta proscrita es suficientemente clara, precisa y taxativa; ii) los autores posibles son todos los ciudadanos, sin que exista falta de predeterminación al respecto, y iii) por más que la norma fije una horquilla de sanciones que concretar discrecionalmente por el órgano aplicador, la cercanía cuantitativa de las cantidades máximas y mínimas garantiza suficientemente la seguridad jurídica de los ciudadanos. Finalmente, en relación con la atribución a los directores de periódico de la responsabilidad por la realización de las conductas prohibidas desde su medio, el Tribunal descarta la existencia de un sistema de responsabilidad objetiva, considerando que se trata de la simple consecuencia del incumplimiento de su deber de cuidado, dado que el director 
tiene derecho de veto de todo lo publicado. Por todo ello, la sentencia desestima la inconstitucionalidad de los artículos cuestionados.

Formula un voto particular concurrente el magistrado D. Juan Antonio Xiol Ríos, al que se adhiere la magistrada Dńa. Encarnación Roca Trías. En él se manifiesta la conformidad con el fallo de la sentencia, pero se discrepa del entendimiento realizado por esta sobre la llamada jornada de reflexión. En su opinión, la finalidad de tal jornada no es la de "crear un marco de serenidad en las horas inmediatamente anteriores a la votación para que en esta aflore sin condicionamientos la verdadera voluntad política del elector", como afirma la sentencia, sino la garantía de una mayor igualdad de oportunidades de las distintas candidaturas, evitando que las más poderosas puedan acaparar la atención mediática las horas previas a la votación.

Asimismo, formula un voto particular la magistrada Dńa. María Luisa Balaguer Callejón, entendiendo que la sentencia debió estimar la cuestión. En su criterio, hubo de darse a la libertad de información del art. 20.1 d) CE una posición nuclear en la argumentación, dada su importancia capital para la formación libre de la voluntad ciudadana. Desde esa perspectiva, afirma, sí se encuentra una relevante indefinición en el precepto cuestionado.

La STC 15/2021, de 28 de enero, resuelve la cuestión planteada por la Sección Segunda de la Sala de lo Contencioso-Administrativo del Tribunal Superior de Justicia del País Vasco en relación con el art. 3.4 de la Ley del Parlamento Vasco 3/1998, de 27 de febrero, general de protección del medio ambiente del País Vasco. Tal norma establece que será pública la acción para exigir el cumplimiento de la ley, en vía tanto administrativa como jurisdiccional. El Tribunal recuerda que las reglas de legitimación procesal se incardinan en el título competencial del art. 149.1.6 CE. Este no realiza una reserva absoluta de la legislación procesal en favor del Estado, sino que admite "las necesarias especialidades que en este orden se deriven de las particularidades del derecho sustantivo de las comunidades autónomas». Sin embargo, el Tribunal no aprecia conexión directa entre la ampliación realizada del ejercicio de la acción pública y las peculiaridades del ordenamiento sustantivo autonómico. En consecuencia, se procede a declarar la inconstitucionalidad de la norma cuestionada. sido tres.

C) Las sentencias dictadas en conflictos positivos de competencia han

La STC 36/2021, de 18 de febrero, resuelve el conflicto planteado por el Gobierno de Cataluña en relación con diversos preceptos del Reglamento de adopción internacional aprobado por el Real Decreto 165/2019, de 22 
de marzo. El Tribunal recuerda que las comunidades autónomas pueden llevar a cabo en el ejercicio de sus competencias actividades con proyección exterior, siempre que respeten el título competencial del Estado en materia de relaciones internacionales (art. 149.1.3 CE), que brinda a este capacidades de coordinación de aquellas actividades. Sobre esa base, el Tribunal analiza caso por caso si los preceptos estatales impugnados encajan cabalmente en la competencia estatal de dirección y coordinación de la política exterior. Así, se estiman constitucionales: i) la competencia del Estado para firmar acuerdos bilaterales de carácter administrativo en materia de adopción internacional (art. 5 RAI); ii) la atribución a un órgano estatal de las decisiones sobre iniciación, suspensión o paralización de los expedientes con un determinado país (arts. 6, 7, 8.2, 3 y 4 RAI); iii) el establecimiento y distribución del número máximo de expedientes que tramitar anualmente con cada país de origen (arts. 10 y 11 RAI); iv) la extensión de la facultad de los organismos intermediarios acreditados para intervenir en procesos de adopción en todo el territorio nacional (art. $12 \mathrm{RAI}$ ), y v) la atribución a la Comisión delegada de servicios sociales de la aprobación del modelo básico del contrato que suscribir entre los organismos intermediarios acreditados y los adoptantes (arts. 31 y 32 RAI). Por el contrario, el Tribunal considera que exceden de las facultades de coordinación del Estado en materia de política exterior, invadiendo las competencias ejecutivas autonómicas en la materia, los siguientes aspectos del Reglamento cuestionado: i) diversas facultades sobre la acreditación de organismos intermediarios (arts. 22.1, 4, 6, 7, y 8, 23.4 y 6, 24, 25.1, 26.1, 27, 28.1 y 30.2 RAI); ii) la regulación exhaustiva del régimen jurídico de tales organismos intermediarios (arts. 13 a $30 \mathrm{RAI}$ ); iii) diversas facultades sobre el seguimiento y control de los organismos acreditados (arts. 15, 29.e y 33.1 RAI), y iv) ciertas facultades de gestión del registro nacional de organismos acreditados (arts. 38.2 y 4, 39.3.b, 39.4.c y 39.4.e RAI). En consecuencia, se estima parcialmente el conflicto planteado. El fallo realiza dos precisiones de interés. En primer lugar, la declaración de inconstitucionalidad se extiende, en virtud del art. 67 LOTC, a los arts. 7.2, párrafo primero, 7.7, inciso «la administración general del Estado, a iniciativa propia o a propuesta de las entidades públicas en su ámbito territorial», y 8.1, inciso "que se encuentre acreditado por la administración general del Estado", de la Ley 54/2007, de 28 de diciembre, de adopción internacional. En segundo lugar, se difieren los efectos de la nulidad por el plazo de un ańo a partir de la publicación de la sentencia, con la finalidad de evitar que un vacío normativo inmediato perjudique a los menores de edad.

Formula un voto particular el magistrado D. Ricardo Enríquez Sancho, al que se adhiere el magistrado D. Santiago Martínez-Vares García. En él se 
argumenta que la competencia autonómica en materia de protección de menores (art. 166.3 EAC) no abarca la intervención en la fase extrajudicial de la adopción internacional que tiene lugar en el extranjero, por lo que en su opinión procedía la desestimación íntegra del conflicto.

La STC 37/2021, de 18 de febrero, resuelve el conflicto planteado por el Gobierno vasco en relación con diversos preceptos del Real Decreto 130/2019, de 8 de marzo, por el que se regula la base de datos nacional de subvenciones y la publicidad de las subvenciones y demás ayudas públicas. El Tribunal recuerda su doctrina asentada en la Sentencia 100/2019, que establece que en ningún caso se puede regular mediante real decreto la actividad administrativa de los Parlamentos territoriales, por más que el contenido material de la disciplina establecida pueda respetar la autonomía que tienen estatutariamente reconocida. Sobre esta base, el Tribunal anula el art. 3.1 de la norma impugnada (en su inciso «legislativos y»), que contemplaba la obligación de los órganos legislativos autonómicos de suministrar determinada información a la base de datos regulada. Respecto de la exigencia realizada por el art. 6 de que se incluyan en la base de datos los textos de las convocatorias de ayudas y subvenciones que realicen las comunidades "con antelación suficiente», el Tribunal lo considera una previsión de mínimos perfectamente encuadrable en la competencia estatal de regulación de las bases del régimen jurídico de las Administraciones públicas (art. 149.1.18 CE), que no condiciona en exceso ni paraliza el ejercicio de la acción administrativa autonómica.

La STC 39/2021, de 18 de febrero, resuelve el conflicto planteado por el Gobierno de la Junta de Andalucía en relación con el art. 5.3 a) del Real Decreto 498/2020, de 28 de abril, por el que se desarrolla la estructura orgánica básica del Ministerio de Educación y Formación Profesional. Al realizar el correspondiente deslinde competencial el Tribunal estima que las normas controvertidas se incardinan en la materia «legislación laboral» (art. 149.1.7 CE y art. 63.1, apdos. 1 y 2 EAAnd), lo cual, a su vez, conduce a afirmar que «la competencia controvertida corresponde a la comunidad autónoma, de suerte que el inciso "y las autonómicas" del art. 5.3 a) del Real Decreto 498/2020 es contrario al orden de distribución de competencias y, por tanto, inconstitucional y nulo».

D) El número de recursos de amparo ha sido de 78.

De conformidad con el fallo, han resultado estimatorias 62; parcialmente estimatorias, 1 , de ambas han tenido el carácter de devolutivas 53 . El número de sentencias desestimatorias ha sido de 14 . 
La STC 52/2021, de 15 de marzo, inadmite el recurso planteado por prematuro.

Los actores se clasifican de la siguiente forma:

- Particulares: 36.

- Entidades mercantiles: SL, 27; SLU, 1; SA, 3.

- Universidad privada: 4.

- Generalitat de Cataluña: 1.

- Cargo representativo: 5.

- Candidatos: 1.

La STC 1/2021, de 25 de enero, considera que la denegación de la pensión de viudedad a una mujer casada que convivía con el causante no vulnera la igualdad. El Tribunal recuerda las circunstancias específicas que dieron lugar a la STEDH Muñoz Díaz c. España. La regulación actual permite recibir pensión de viudedad a parejas de hecho, pero siempre que estas hayan sido inscritas; esta exigencia no puede considerarse una discriminación por motivos étnicos. Tampoco se produce discriminación indirecta, pues la norma se aplica a los miembros de la etnia gitana que han optado por no formalizar su unión igual que cualquier otra persona que tome esa decisión por cualquier motivo. El magistrado D. Juan Antonio Xiol Ríos formula voto particular discrepante, en el cual expone que, a pesar de la aparente neutralidad de la medida, ocasiona una desventaja particular estadísticamente significativa, ocasionando, así, una discriminación indirecta.

Una vulneración de la igualdad y de la presunción de inocencia se aprecia en la STC 41/2021, de 3 de marzo, siguiendo la doctrina de la STC 125/2019, a su vez en aplicación de la anulación de precepto legal efectuada por la STC 85/2019. En similar sentido, STC 83/2021, de 19 de abril.

Las SSTC 2 y 6/2021, ambas de 25 de enero, la primera con un voto particular del Sr. Xiol, la segunda con dos votos particulares, uno del Sr. Conde-Pumpido y otro de la Sra. Balaguer, reiteran el asunto resuelto en la STC 191/2020, al igual que la STC 19/2021, de 15 de febrero, y la STC $42 / 2021$, de 3 de marzo, a la que se adjunta un voto particular del Sr. Xiol.

El derecho a la igualdad y el derecho a la no discriminación se debaten en la STC 51/2021, de 15 de marzo. En ella el Tribunal, tras recordar la normativa y la doctrina aplicable al derecho a no ser discriminado por razón de discapacidad y, en su caso, la admisibilidad de medidas positivas para facilitar la integración, así como la distribución de la carga de la prueba y su aplicación por la Administración, analiza los ajustes razonables en el ámbito del empleo, con especial referencia a la discapacidad mental (en el caso se aducía 
síndrome de Asperger), destacando el deber de motivar la imposibilidad o improcedencia de efectuar los ajustes solicitados; asimismo, señala que se incurriría en discriminación al imponer medidas como el despido o sanciones de carácter disciplinario que pudieran evitarse con la adopción de las pertinentes medidas de adaptación. La motivación manifiestamente insuficiente por parte de la Administración aboca a que el Tribunal estime la vulneración no solo del art. $14 \mathrm{CE}$, sino también de los arts. 24.2 y $25.1 \mathrm{CE}$ en lo atinente a las carencias en el procedimiento administrativo y en el respeto a la presunción de inocencia.

La STC 81/2021, de 19 de abril, estudia la supuesta vulneración del derecho a la educación (art. 27), así como a la igualdad y a la no discriminación (art. 14), a la tutela judicial efectiva y a la presunción de inocencia (art. 24) y a la integridad física y moral (art. 15). Los hechos consisten en que el hijo de los recurrentes protagoniza en el colegio episodios (cada vez más habituales) de violencia contra otros niños, profesores e incluso contra sí mismo. El centro va implantando distintas medidas para tratar de revertir la situación, pero ante el aumento de estos episodios decide la suspensión de la asistencia al centro hasta que aporte un informe psiquiátrico que permita tratar la situación adecuadamente; hasta ese momento, se facilitarán a los padres información y recursos pedagógicos para evitar perjuicios a nivel educativo. El Tribunal considera que, valorando la resolución recurrida en su conjunto, se han razonado y motivado suficientemente las razones para adoptar la medida, teniendo en cuenta el interés superior del menor. La aludida vulneración al derecho a la igualdad debe descartarse por no haberse proporcionado un término de comparación. En relación con la integridad física, según consta en los hechos, la contención física se hacía precisamente para evitar daños mayores a sí mismo o a otros menores, por lo que también debe ser descartada su vulneración. Por último, tampoco se da la vulneración de la tutela judicial efectiva, puesto que la medida no responde a una sanción.

El magistrado D. Juan Antonio Xiol Ríos formula voto particular discrepante al considerar que no había habilitación legal para suspender la asistencia del alumno al centro escolar (lo que vulneraría el derecho a la educación) y al hacerlo sospechando una discapacidad psíquica se vulnera también el derecho a la igualdad y no discriminación; por otro lado, mantiene que no existe habilitación legal para el uso sistematizado de medidas de contención física y, por tanto, se habría invadido la integridad física y moral del niño.

La STC 73/2021, de 18 de marzo, examina una vulneración de la libertad personal, en primer lugar, por haberse dilatado la puesta a disposición judicial tras la solicitud de habeas corpus, y, en segundo lugar, por haber inadmitido el citado procedimiento por motivos de fondo en contra de lo expresado en la 
LOHC y en una dilatada jurisprudencia. Formulan sendos votos particulares discrepantes el Sr. Narváez, al que se adhieren los Sres. Martínez-Vares y Montoya, y el Sr. González-Trevijano.

Una vulneración del derecho a la libertad personal conjuntamente con el derecho a la tutela judicial es el objeto de la STC 80/2021, de 19 de abril, en la cual el Tribunal estima que, a pesar de encontrarse el asunto bajo secreto sumarial, debían haberse puesto en conocimiento de los acusados los elementos esenciales para poder oponerse a la solicitud de prisión provisional.

La STC 5/2021, de 25 de enero, aborda una supuesta vulneración de derechos fundamentales, a las libertades de expresión y de información y de defensa de los derechos procesales. Los recurrentes alegaban la vulneración de su libertad de expresión al haberse dictado una resolución en la que se establecía que un escrito de presidentes de federaciones territoriales de fútbol en apoyo a uno de los candidatos a presidir la Federación vulneraba el principio de neutralidad electoral. En primer lugar, el Tribunal señala que las garantías del art. 24.2 CE únicamente son aplicables al derecho administrativo sancionador, por lo que desestima esa queja. En relación con la queja relativa a la libertad de expresión, el Tribunal recuerda la naturaleza de las federaciones deportivas: entidades privadas que asumen el ejercicio de potestades públicas. Puesto que los recurrentes firman como miembros de las federaciones (y no como ciudadanos), se contravino el principio de neutralidad en período electoral. Además, como órganos federativos no pueden invocar la titularidad de derechos fundamentales, pues se hallaban en el desempeño de funciones públicas.

En la STC 53/2021, de 15 de marzo, el Tribunal trae a colación su consolidada doctrina sobre el control de la Mesa de los Parlamentos del ejercicio de la facultad de veto presupuestario (SSTC 223/2006, 242/2006, 34/2018, 44/2018, 139/2018 y 17/2019), puntualizando que debe distinguirse entre la facultad de veto presupuestario conferida a los Gobiernos y las funciones de control que corresponden a las Mesas de los Parlamentos respectivos. Sobre lo primero recuerda que el alcance temporal de la conformidad del Gobierno ha de referirse siempre al presupuesto en vigor y no respecto de presupuestos futuros, y, además, la motivación del Gobierno debe expresar que la iniciativa tiene incidencia directa e inmediata en el presupuesto vigente. En cuanto a la función de control de la Mesa sobre dicha facultad gubernamental, reitera que se trata de un «control reglado sobre el ejercicio de la facultad del Gobierno, de carácter técnico-jurídico" y de un doble control, formal y material. El Tribunal concluye que el informe en el que se basa el Gobierno no puede considerarse como una justificación adecuada del ejercicio de su facultad de veto presupuestario, dado que no se refiere al impacto directo y actual de las medidas previstas en la 
proposición de ley sobre los créditos presupuestarios vigentes. De igual modo, considera que la Mesa de la Cámara incumplió la función de control que le corresponde a ese órgano parlamentario respecto de la disconformidad planteada por el Gobierno autonómico al no explicitar las razones que permiten considerar acreditado el presupuesto material del impacto directo y actual de la iniciativa legislativa en los créditos presupuestarios vigentes. En consecuencia, estima el recurso de amparo al considerar vulnerado el derecho al ejercicio de cargo público parlamentario (art. 23.2 CE).

La STC 66/2021, de 15 de marzo, desestima el recurso de amparo planteado por treinta y dos diputados del Grupo Parlamentario Ciutadans en el Parlamento de Cataluńa contra varios actos parlamentarios. El recurso examina si, al entender el presidente del Parlamento que el señor Torra i Pla no había cesado como presidente de la Generalitat y, en consecuencia, no iniciar los trámites para una nueva investidura — como solicitaban los recurrentes-, se lesionó el núcleo de sus derechos y facultades como parlamentarios. El Tribunal se encarga de precisar que «la queja realmente deducida es que la mesa y el presidente del Parlamento no han dado debida observancia a lo que los demandantes consideran el "deber de constatar que el señor Torra i $\mathrm{Pla}$ incumple los requisitos para ostentar legítimamente la presidencia de la Generalitat, permitiendo la violación del derecho de representación política"». Sobre el órgano parlamentario que habría incurrido en la falta de actuación denunciada, y aunque los recurrentes dirigen el recurso contra actos de la Mesa y del presidente de la Cámara, el Tribunal precisa que la supuesta lesión habría sido producida por este último, no por la Mesa, puesto que es a quien corresponde la competencia para iniciar una nueva investidura por concurrir una causa de cese del entonces presidente. El Tribunal desestima el recurso porque los recurrentes han ejercido sin restricciones la función de control sobre quien era presidente de la Generalitat. A este respecto, trae a colación lo sostenido en una sentencia anterior, desestimatoria de otro recurso de amparo planteado también por los diputados de Ciutadans en el Parlamento de Cataluña contra omisiones parlamentarias, que no es suficiente invocar «una genérica e inconcreta denuncia de la vulneración de facultades parlamentarias vinculadas al núcleo del ius in officium protegido constitucionalmente a través del art. 23.2 CE» (STC 173/2020, de 19 de diciembre, FJ 4).

En las SSTC 69, 70 y 71/2021, todas de marzo, y 90/2021, de 22 de abril, el Pleno del Tribunal recaba para sí el conocimiento de los recursos de amparo por plantear un problema o afectar a una faceta de un derecho fundamental sobre el que no hay doctrina constitucional y porque los asuntos suscitados trascienden el caso concreto al poder tener consecuencias políticas generales. 
Las SSTC 69 y 90/2021 resuelven sendos recursos de amparo presentados por Jordi Sánchez y Josep Rull, respectivamente, contra los correspondientes acuerdos que desestiman la solicitud de reconsideración presentada contra los acuerdos de la Mesa de la Cámara, complementarios de los acuerdos anteriores, por los que había declarado «automáticamente suspendidos en el ejercicio del cargo y, por tanto, en los derechos y deberes establecidos en el Reglamento de la Cámara» a cuatro diputados, entre ellos a los recurrentes, por concurrir las «circunstancias necesarias para la aplicación» del art. 384 bis LECrim. Los recurrentes alegan que las resoluciones parlamentarias impugnadas vulneraron los arts. 23.2 y $24.2 \mathrm{CE}$.

Con carácter previo el Tribunal resuelve varias cuestiones de orden procesal. Así, confirma que la portavoz del Grupo Parlamentario Mixto puede solicitar a la Mesa de la Cámara la reconsideración, ya que los grupos parlamentarios, en aplicación del principio del favor actionis, ostentan una representación institucional de los miembros que los integran que les otorga capacidad procesal para defender las eventuales vulneraciones de los derechos fundamentales de sus miembros (STC 24/2020). Asimismo, confirma que «el hecho de que el recurrente hubiese sido suspendido en su condición no tiene efectos tampoco en la legitimación de la portavoz para solicitar la reconsideración», puesto que el diputado recurrente forma parte del Grupo Mixto.

Para resolver la principal cuestión de fondo suscitada, relativa a la privación al recurrente de la asignación económica y otros derechos de carácter económico, el Tribunal trae a colación lo decidido en la STC 97/2020 y también otros pronunciamientos previos. Así, recuerda que los derechos de contenido económico no forman parte del núcleo del ius in officium de los diputados autonómicos (STC 159/2019, FJ 6, con remisión a la STC 36/2014, FJ 6). En este sentido, sostiene:

[...] la previsión constitucional de que los diputados percibirán una asignación que será fijada por las respectivas cámaras, ha de ser entendida, como lo ha hecho el artículo 8 RCD, en el sentido de que dicha asignación será la necesaria para el ejercicio de sus funciones. Al ser la asignación un instrumento para el ejercicio de las funciones, su privación comportará la vulneración del art. 23.2 CE solo cuando le impida el ejercicio de las funciones que tiene encomendada. En este caso, sin embargo, es la suspensión de la condición de diputado y por ende de la posibilidad de ejercicio de sus funciones lo que ha determinado la suspensión de la asignación económica.

A ello añade que «la suspensión de los derechos de contenido económico (ATC 334/1993, de 10 de noviembre, FJ 2) no vulnera el artículo 23.2 CE 
precisamente porque se impone por la falta de ejercicio de las funciones parlamentarias» (STC 69/2021, FJ 5.C.c). En consecuencia, ambas sentencias desestiman los recursos de amparo interpuestos.

En las SSTC 70 y 71/2021, el Tribunal se pronuncia sobre idénticos objetos, por lo que serán comentadas conjuntamente. En ambas resoluciones se desestiman dos recursos de amparo presentados por distintos diputados (Oriol Junqueras, Jordi Sánchez, Josep Rull y Jordi Turull) y un senador (Raül Romeva) contra varios autos de la Sala Segunda del Tribunal Supremo en los que se acuerda que no ha lugar a solicitar autorización a las Cámaras legislativas mediante la remisión del suplicatorio para continuar con el juicio oral contra los demandantes de amparo en causa especial, ni a suspender sus sesiones. Los recurrentes alegan vulneración del derecho a la participación y representación política (art. $23 \mathrm{CE}$ ), en relación con la prerrogativa de la inmunidad parlamentaria (art. 71.2 CE), y del derecho a un proceso con todas las garantías (art. 24.2 CE).

Con carácter previo el Tribunal desestima los óbices procesales suscitados en relación con la legitimación y agotamiento de la vía judicial previa. Sobre esto último el Tribunal desestima el supuesto carácter prematuro del recurso. Para ello revisa su doctrina sobre las excepciones a la regla general que requiere la finalización del proceso penal para entender correctamente agotada la vía judicial (STC 130/2018, FJ 5), y considera que, atendiendo a las concretas circunstancias del caso, ha de entenderse agotada la vía judicial previa, sin necesidad de que hubiera que esperar a la conclusión del proceso penal antes de acudir en amparo, puesto que imponer el seguimiento exhaustivo del proceso penal en todas su fases o etapas hasta su conclusión definitiva «supondría una rigorista exigencia del cumplimiento del requisito del agotamiento de la vía judicial, que implicaría, de estimarse la pretensión de amparo, quizás no un perjuicio irreparable, pero sí, al menos, un gravamen adicional o una mayor intensidad en la lesión del derecho fundamental por su mantenimiento en el tiempo» (FJ 2.B.c).

Para resolver la cuestión de fondo el Tribunal acude a su doctrina jurisprudencial sobre la prerrogativa de la inmunidad parlamentaria y a los criterios que se desprenden de la jurisprudencia del TEDH y del TJUE. De este modo, examina si la interpretación que la Sala Segunda del Tribunal Supremo efectuó de la prerrogativa de inmunidad parlamentaria, en virtud de la cual decidió no solicitar la autorización de las Cámaras para continuar el proceso penal contra los demandantes, se cohonesta o no con el alcance, sentido y finalidad con los que la prerrogativa de inmunidad se reconoce en el texto constitucional (art. 71.2 CE) y si resulta lesiva de los derechos fundamentales alegados por los recurrentes. 
El Tribunal constata que el constituyente acotó el ámbito de protección de la prerrogativa de la inmunidad de los diputados y senadores ex art. 71.2 $\mathrm{CE}$ a través de una doble delimitación, «su ámbito material, que comprende la prohibición de la detención, salvo en caso de flagrante delito, y la previa autorización de la cámara respectiva para que los diputados y senadores puedan ser "inculpados" o "procesados"; y, su ámbito temporal, que se extiende a todo el periodo del mandato parlamentario» (FJ 5.a). De este modo, concluye que la interpretación sostenida por la Sala es conforme con el sentido del art.71.2 CE, que «no requiere la previa autorización de la cámara respecto de quien, encontrándose ya procesado o inculpado, adquiera sobrevenidamente la condición de diputado o senador en la fase del juicio oral» (FJ 6). En consecuencia, la decisión de la Sala Segunda del Tribunal Supremo de no solicitar la autorización al Congreso de los Diputados y al Senado para continuar el proceso penal contra los demandantes de amparo no vulnera el derecho fundamental al ejercicio del cargo público representativo (art. 23.2 CE), ni, en consecuencia, el derecho a un proceso con todas las garantías (art. 24.2 CE). El Tribunal descarta la extensión de la prerrogativa de la inmunidad hasta el momento del dictado de la sentencia, como sostuvieron los recurrentes, ya que no se ajusta al tenor del art. 71.2 CE, ni se cohonesta con su finalidad institucional, ni es congruente con una interpretación restrictiva de esta (FJ 6.b).

En la STC 76/2021, de 19 de abril, el Tribunal Constitucional desestima el recurso de amparo electoral presentado por Antonio Cantó García del Moral y Agustín Conde Bajén contra la sentencia de Juzgado de lo Contencioso-Administrativo n. 5 de Madrid, que estimó el recurso contencioso-electoral promovido por el PSOE, y anuló parcialmente el acuerdo de la Junta Electoral Provincial de Madrid de 7 de abril de 2021, por el que se proclamó definitivamente la candidatura del Partido Popular para las elecciones autonómicas del 4 de mayo de 2021, acordando que los recurrentes en amparo, candidatos en dicho proceso electoral, debían excluirse de esta, por ser inelegibles. A juicio de los demandantes la resolución recurrida vulneró varios derechos fundamentales. En primer lugar, el derecho de sufragio pasivo, en la medida en que la sentencia impugnada impuso ex novo un requisito no previsto legalmente para poder ser candidato, y por haber realizado una interpretación restrictiva y no favorable a la efectividad del derecho fundamental. El Tribunal desestima esta queja al considerar que la «interpretación que realiza la resolución judicial impugnada es absolutamente coherente y respetuosa con la garantía institucional de la representación política resultante del art. $23 \mathrm{CE}$ ( FJ 4.e). En cuanto a la segunda queja alegada por los recurrentes, relativa al derecho de acceso en condiciones de igualdad a cargos públicos electivos, es igualmente desestimada al entenderse subsumida en la primera. 
Por último, los demandantes formulan una tercera queja relativa a la supuesta vulneración del derecho a la tutela judicial efectiva, respecto de la cual el Tribunal considera que carece de desarrollo argumental, lo que excusa su examen.

La sentencia va acompañada de tres votos particulares formulados, respectivamente, por el magistrado D. Andrés Ollero, el magistrado D. Santiago Martínez-Vares y el magistrado D. Alfredo Montoya.

Una vulneración del derecho al principio de legalidad penal, junto con la vulneración del derecho a la tutela judicial efectiva sin indefensión, en su vertiente de acceso al recurso, es el objeto de la STC 78/2021, de 19 de abril. La resolución del recurso por el Tribunal empieza inadmitiendo la parte de las alegaciones referidas a la vulneración de la tutela judicial efectiva por el Tribunal Supremo, al entender que no se ha agotado la vía jurisdiccional previa, al haber recurrido la parte actora a la petición de aclaración y no al incidente de nulidad de actuaciones, el remedio idóneo para la reparación de eventuales violaciones de derechos fundamentales ante la última instancia. Niega, sin embargo, que la inadmisión deba afectar "por arrastre» a las vulneraciones del principio de legalidad penal imputadas a los órganos penales de instancia y apelación. Enmarca la Sala su decisión dentro de la tarea de evaluar la sostenibilidad constitucional de la concreta interpretación de las normas penales realizada por los órganos judiciales (seguridad jurídica, tipicidad y razonabilidad jurídica tanto de la interpretación de la norma como de la operación de subsunción de los hechos en el supuesto de hecho). Concluyendo que sí fue vulnerado el derecho fundamental a la legalidad penal al no haber considerado decaída la medida cautelar de alejamiento una vez sobreseído provisionalmente el proceso penal en contra del ahora recurrente.

La sentencias concernientes al derecho a la tutela judicial efectiva pueden clasificarse de la siguiente forma:

a) Comunicación procesal: SSTC 9 y 10/2021, ambas de 25 de enero, y SSTC 25, 26, 27, y 28/2021, todas de 15 de febrero, SSTC 30, 31, 32, 33/2021, todas del 5 de febrero, SSTC 44, 45, 46, 47, 48 y 49/2021, todas de 3 de marzo, SSTC 56, 58, 59 y 62/2021, todas de 15 de marzo, y SSTC 84, 85, 86 y 89/2021, todas de 19 de abril, en las que se sigue reiterando la doctrina expresada en aplicación de las STC 6 y 47/2019. La STC 20/2021, de 15 de febrero, conforme a lo ya expresado en la STC 62/20. Las SSTC 43/2021, de 3 de marzo, 64/2021, de 15 de marzo, 82/2021, de 19 de abril, y 87/2021, de 19 de abril, estiman los recursos por haber procedido indebidamente a emplazamientos por edictos. 
En la STC 79/2021, de 19 de abril, alega la parte actora el perjuicio causado por el cambio de plataforma de comunicación telemática que el Juzgado de Primera Instancia n. ${ }^{\circ} 8$ de Zaragoza venía utilizando con su representación procesal desde el comienzo del procedimiento ordinario (Lexnet) a la Avantius-Aragón, sin que esa circunstancia fuera comunicada personal o institucionalmente a dicha representación procesal, lo que implicó que no tuvieran efectivo conocimiento de la sentencia condenatoria recaída en el procedimiento, con la pérdida de oportunidad de formulación del recurso de apelación. El Tribunal resuelve estimando el amparo al considerar que se ha otorgado un valor automático al simple acto formal de la puesta a disposición de la notificación de la sentencia en la nueva plataforma telemática sin ponderar adecuadamente las razones por las que no se pudo tomar conocimiento efectivo de dicha resolución ante la ausencia de cualquier tipo de comunicación personal, institucional u oficial del cambio de plataforma telemática a través de la cual se debía dar cumplimiento a la obligación de comunicación electrónica con el juzgado en el procedimiento.

b) Motivación: SSTC 7, 8 y 12/2021, todas de 25 de enero, 24/2021, de 15 de febrero, y 50/2021, de 3 de marzo, y 77/2021, de 19 de abril, en las que se sigue la doctrina de la STC 31/2019. Las SSTC 7 y 50 cuentan ambas con un voto particular del Sr. Enríquez. La STC $55 / 2021$, de 15 de marzo, que reitera la jurisprudencia de la STC 46/2020, mientras que la STC 57/2021, de 15 de marzo, lo hace de la STC 151/2020. SSTC 61/2021, de 15 de marzo, 65/2021, de 15 de marzo, y 67/2021, de 17 de marzo. La STC 88/2021, de 19 de abril, reviste carácter estimatorio, puesto que la sentencia recurrida «se apoya sobre unos presupuestos de hecho y de derecho que no dan respuesta argumentativa a los que la demandante de amparo acreditó como realidad jurídica verdadera», como resultado de una sentencia civil que acreditaba la existencia de una titularidad dominical.

c) Acceso a la jurisdicción: STC 23/2021, de 15 de febrero, que reitera la STC 17/2020, en aplicación de la STC 15/2020; en el mismo sentido, STC 54/2021, de 15 de marzo. STC 63/2021, de 15 de marzo, en la que se reitera, conforme reiterada doctrina, que la Administración no puede verse favorecida por defectos de su propia actuación; por otro lado, se llevó a cabo una interpretación de las normas de derecho transitorio que vulneraba el derecho de acceso a la jurisdicción para así permitir el control de la actividad administrativa requerido.

d) Derecho a la tutela judicial efectiva sin indefensión: STC 60/2021, de 15 de marzo, que sigue lo establecido en la STC 62/2020. 
e) Acceso a los recursos: STC 11/2021, de 25 de enero, en la que remite a la jurisprudencia establecida en las SSTC 128/2018 y 98/2020.

f) Derecho a la defensa y a la presunción de inocencia: STC 21/2021, de 15 de febrero, que, siguiendo doctrina propia y del TEDH, considera que se ha quebrado la garantía de no autoincriminación.

g) Derecho a un proceso con todas las garantías y a la presunción de inocencia: STC 22/2021, de 15 de febrero, en la que se desestiman las pretensiones del recurrente; cuenta con un voto particular el Sr. Xiol.

h) Resolución fundada en derecho: STC 17/2021, de 15 de febrero, en la que se estima una vulneración del art. 24.1 CE, dado que la resolución judicial revisó la aplicación del derecho sustantivo de las resoluciones arbitrales, frente a la asentada doctrina de que solo cabrá la revisión de los errores in procedendo.

i) Derecho a la defensa y a un proceso con todas las garantías: STC 35/2021, de 18 de febrero.

j) Derecho a un proceso con todas las garantías: SSTC 3 y 4/2021, de 25 de enero, en su dimensión del derecho a una segunda instancia penal revisora de una declaración de culpabilidad. La sentencia indicaba erróneamente cómo recurrir e inadmite ese recurso; se rectifica la sentencia de instancia pero al plantear el recurso el tribunal declara la nulidad de la rectificación, dejando al recurrente sin posibilidad de segunda instancia penal.

k) Derecho a la tutela judicial efectiva, a un proceso con todas las garantías y a la presunción de inocencia: STC 18/2021, de 15 de febrero, que rechaza los argumentos de la parte actora al interpretar que el Tribunal Supremo no se extralimitó en sus atribuciones. Formula un voto particular discrepante el magistrado Sr. Xiol.

1) Derecho a la tutela judicial efectiva: STC 25/2021, de 15 de febrero.

m) Asistencia letrada y asistencia jurídica gratuita: STC 29/2021, de 25 de febrero. Ante la personación de una nueva acusación particular en un proceso, se determina la aplicación del art. 113 LECrim, que establece la posibilidad de que se imponga judicialmente la actuación bajo una misma dirección y representación en un procedimiento cuando sean dos o más las personas que ejerciten las acciones derivadas de un delito, sin valorarse que esta acusación es beneficiaria de la asistencia jurídica gratuita, circunstancia que debe ser tomada en consideración por su relevancia y peculiar estatus.

n) Derechos a la tutela judicial efectiva (resolución fundada en derecho), al juez ordinario predeterminado por la ley y a la doble instancia penal: STC 34/2021, de 17 de febrero. La asunción inicial de la 
investigación por el Tribunal Supremo (y no el Tribunal Superior de Justicia, como reclamaba la recurrente) no se basó en criterios arbitrarios, manifiestamente irrazonables o fruto de un error patente. En relación con la inexistencia de segunda instancia penal cuando se ha sido juzgado en primera por el Tribunal Supremo, el Tribunal lo desestima remitiéndose a su jurisprudencia previa. Por otro lado, el cálculo de la multa impuesta tampoco puede calificarse de arbitrario, manifiestamente irrazonable o fruto de un error patente.

La STC 91/2021, de 22 de abril, desestima la alegada vulneración de los derechos al juez ordinario predeterminado por la ley y de defensa, a un proceso con todas las garantías y a la presunción de inocencia, a la tutela judicial efectiva y a la legalidad penal. El Tribunal asienta su argumentación en una extensa resolución, de la que a continuación se extraen sus principales elementos:

1) Frente a la pretendida lesión de los derechos al juez ordinario predeterminado por la ley y al doble grado de jurisdicción penal (art. 24.2 CE), el Tribunal descarta, en primer lugar, que la determinación de la competencia objetiva por el Tribunal Supremo se apoyara en argumentos arbitrarios, manifiestamente irrazonables o fruto de un error patente. En segundo lugar, recuerda que en casos de aforamiento ante el Tribunal Supremo, incluso cuando, en atención a las reglas procesales de conexión, el enjuiciamiento en única instancia se extiende a personas no aforadas, la restricción del derecho a someter la declaración de la pena y la culpabilidad ante un tribunal superior encuentra justificación suficiente.

2) Frente a la pretendida lesión de los derechos de defensa y a no ser discriminado por razón de la lengua (arts. 24 y 14 CE), el Tribunal subraya que el derecho a ser asistido de intérprete (derivado directamente de la Constitución, al entenderse comprendido en el art. 24.1 $\mathrm{CE}$, en cuanto dispone que en ningún caso puede producirse indefensión) se extiende a los españoles que no conozcan suficientemente el castellano - los que no lo comprendan o no lo hablen - y no solo a los extranjeros que se encuentren en ese caso. Sin embargo, como establece la sentencia, resultaba público y notorio que el acusado dominaba a la perfección el castellano, por lo que no cabe hablar de indefensión alguna.

3) Frente a la pretendida lesión del derecho a un juez imparcial (art. 24.2 $\mathrm{CE})$, el Tribunal indica, en primer lugar, que las recusaciones 
planteadas contra el magistrado instructor y contra uno de los magistrados de la sala de recursos no fueron planteadas en el momento procesal oportuno, tal y como exige el art. $44.1 \mathrm{c}$ ) LOTC. En segundo lugar, descarta vulneración del derecho en la denegación de la recusación planteada contra aquellos magistrados de la sala de enjuiciamiento que habían formado parte de la sala de admisión, pues «la admisión a trámite de una querella no prejuzga la existencia de delito ni su autoría». En tercer lugar, se niega que la pertenencia de los magistrados de la sala de enjuiciamiento al mismo Tribunal que el magistrado instructor genere lesión del derecho alegado, pues lo relevante es el adecuado deslinde funcional entre ellos, no pudiendo el último formar parte de aquella. En cuarto lugar, sobre la inadmisión de la recusación planteada contra el presidente de la sala de enjuiciamiento por un mensaje de Whatsapp emitido por un senador del Partido Popular en el que se hablaba de la designación del magistrado como eventual presidente del Consejo General del Poder Judicial y afirmando que ello permitiría "controlar la sala segunda por detrás», el Tribunal subraya que la imparcialidad de un magistrado solo puede ponerse en cuestión por conductas o expresiones del propio magistrado, y no por las de un tercero. En quinto lugar, y respecto de un supuesto rol inquisitivo del presidente de la sala en la declaración de uno de los testigos, el Tribunal confirma que la potestad del tribunal de realizar preguntas a un testigo sobre aspectos fácticos que no le hayan quedado claros ha sido ejercida correctamente, toda vez que el presidente planteó una pregunta sobre un aspecto incluido en los escritos de acusación y que también había sido planteada ya en el juicio oral.

4) Frente a la alegada vulneración del derecho a la igualdad de armas (art. 24.2 CE), el Tribunal considera que los supuestos agravios relatados por el recurrente no tienen suficiente entidad como para generar una disminución real y efectiva de sus garantías procesales.

5) Frente a la pretendida lesión del derecho a la prueba (art. $24 \mathrm{CE}$ ), el Tribunal recuerda que corresponde a los jueces y tribunales el examen sobre la legalidad y la pertinencia de las pruebas, no pudiendo él sustituir o corregir la actividad de estos, sino tan solo controlar que la interpretación y aplicación de la legalidad no ha sido arbitraria e irrazonable. En este sentido, el Tribunal no detecta arbitrariedad alguna ni falta de motivación en las decisiones de la sala.

6) Frente a la alegada violación del derecho a la presunción de inocencia (art. 24.2 CE), el Tribunal subraya que el recurrente censura 
únicamente unas declaraciones de una secretaria de Estado, ajenas al tribunal sentenciador. Tratándose de una imputación que no se realiza a la sentencia recurrida, el Tribunal omite entrar en su consideración.

7) Frente a la posible vulneración del derecho a un proceso con todas las garantías (art. 24.2 CE) por la filtración del contenido de la sentencia antes de su notificación a las partes, el Tribunal entiende que no queda acreditado que las noticias aparecidas en medios de televisión sobre el posible sentido de la sentencia provinieran de algún miembro de la sala enjuiciadora.

8) Frente a la alegada lesión del derecho a un proceso con todas las garantías (art. 24.2 CE) por la imposición de una pena superior a lo solicitado por las acusaciones, el Tribunal constata que la pena impuesta no excede la más grave de las interesadas por los acusadores.

9) Frente a la posible lesión del derecho a la legalidad penal (art. 25.1 CE), el Tribunal entiende, en primer lugar, que el delito de sedición regulado en el art. $544 \mathrm{CP}$ no adolece de un grado de vaguedad tal que infrinja el mandato constitucional de taxatividad, siendo posible conocer de antemano las conductas susceptibles de ser castigadas. En segundo lugar, la pena impuesta no se considera desproporcionada, al no apreciarse desequilibrio manifiesto y no justificable entre esta y la finalidad de la norma punitiva.

Formulan voto particular conjunto los magistrados Sr. Juan Antonio Xiol Ríos y Sra. María Luisa Balaguer Callejón. Entienden los magistrados que sí se produce lesión del derecho a la legalidad penal por haberse impuesto una pena desproporcionada. En su criterio, existían suficientes circunstancias para que la concreción de la pena dentro de los márgenes legales hubiera sido más favorable para el acusado, destacando el hecho de que la aplicación del delito se realizó sobre dos actos que, al margen de que pudieran suponer una confrontación con decisiones jurisdiccionales, se desenvolvían en el contexto del derecho de reunión pacífica y se desarrollaron con solo puntuales incidentes. Así, afirman que debió evitarse que fuera impuesta una sanción excesivamente severa contra un ejercicio que, «aunque extralimitado e ilegítimo, se desarrollaba en la órbita de protección de este derecho y, por tanto, debía evitarse que se generara un efecto desaliento.

Las resoluciones recurridas se distribuyen de la siguiente manera: 


\begin{tabular}{lcccc}
\hline \multicolumn{1}{c}{ Órgano } & Sentencia & Auto & Providencia & Decreto \\
\hline Tribunal Supremo & 7 & 3 & 5 & \\
TSJ & 5 & 5 & 1 & \\
Audiencia Nacional & 1 & 1 & & \\
Audiencia Provincial & & 37 & & \\
Juzgado de 1.a Instancia & & 3 & 1 & 1 \\
Juzgado de lo Penal & 1 & & & 1 \\
\hline
\end{tabular}

Resoluciones de Mesa de Parlamento: 5.

Resolución del Tribunal Administrativo del Deporte: 1.

En el período se han formulado votos particulares, alguno de ellos firmado por más de un magistrado y otros que cuentan con adhesiones. Los magistrados que los han formulado han sido los siguientes:

- Sra. Balaguer Callejón: 5

- Sr. Conde-Pumpido Tourón: 2

- Sr. Enríquez Sancho: 4

- Sr. González-Trevijano Sánchez: 2

- Sr. Martínez-Vares: 1

- Sr. Montoya Melgar: 1

- Sr. Narváez Rodríguez: 1

- Sr. Ollero Tassara: 1

- Sra. Roca Trías: 1

- Sr. Xiol Ríos: 9 

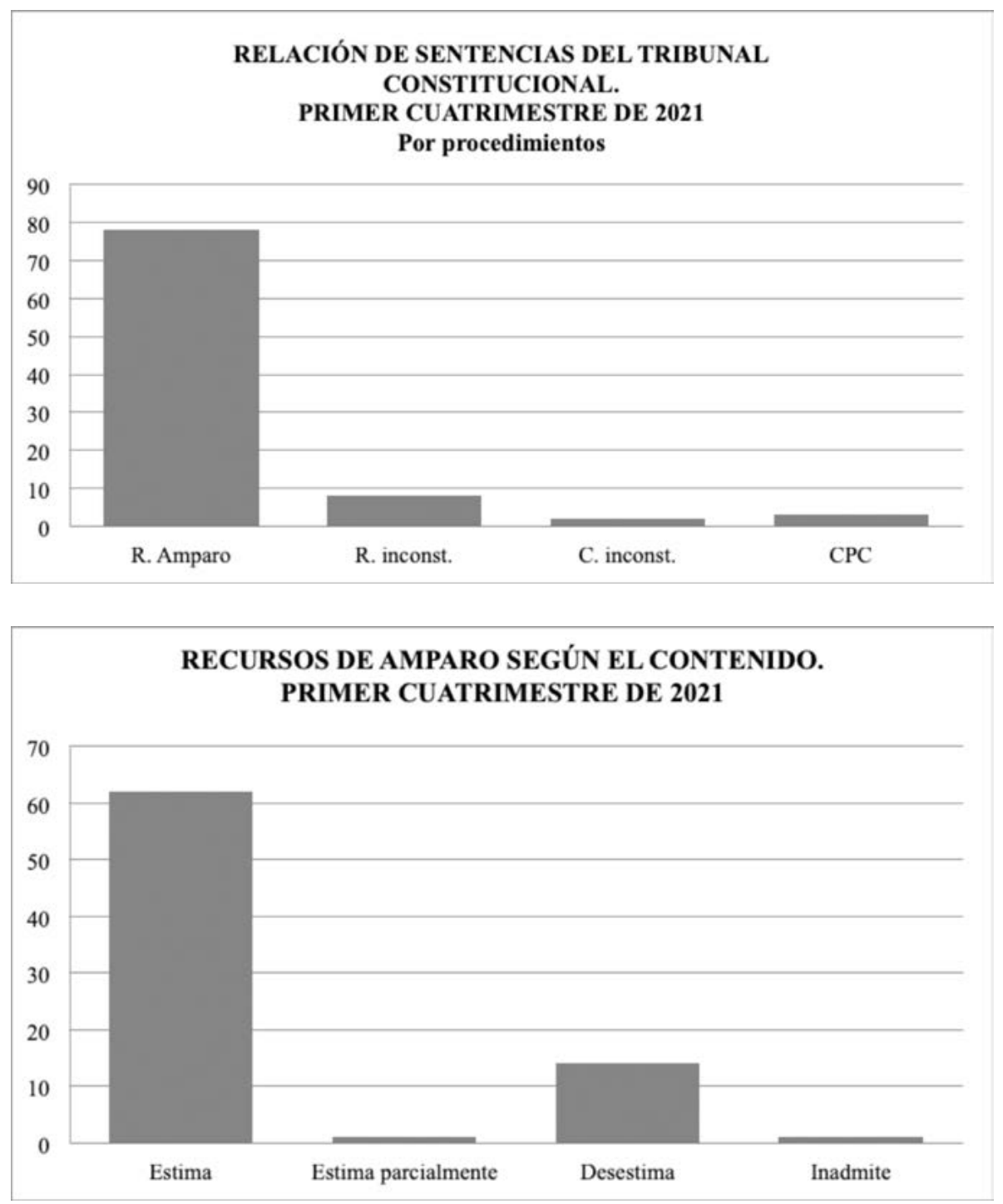

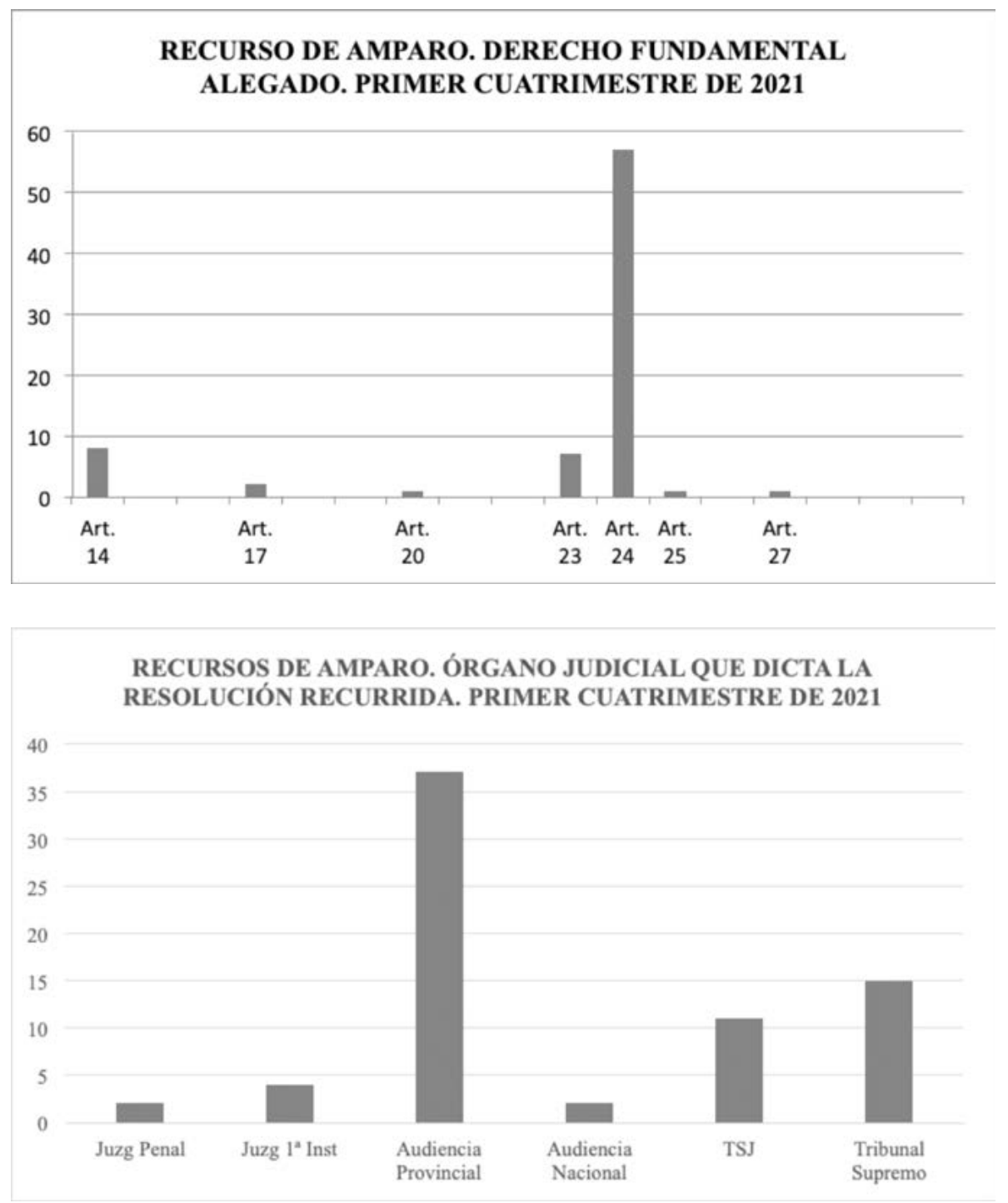


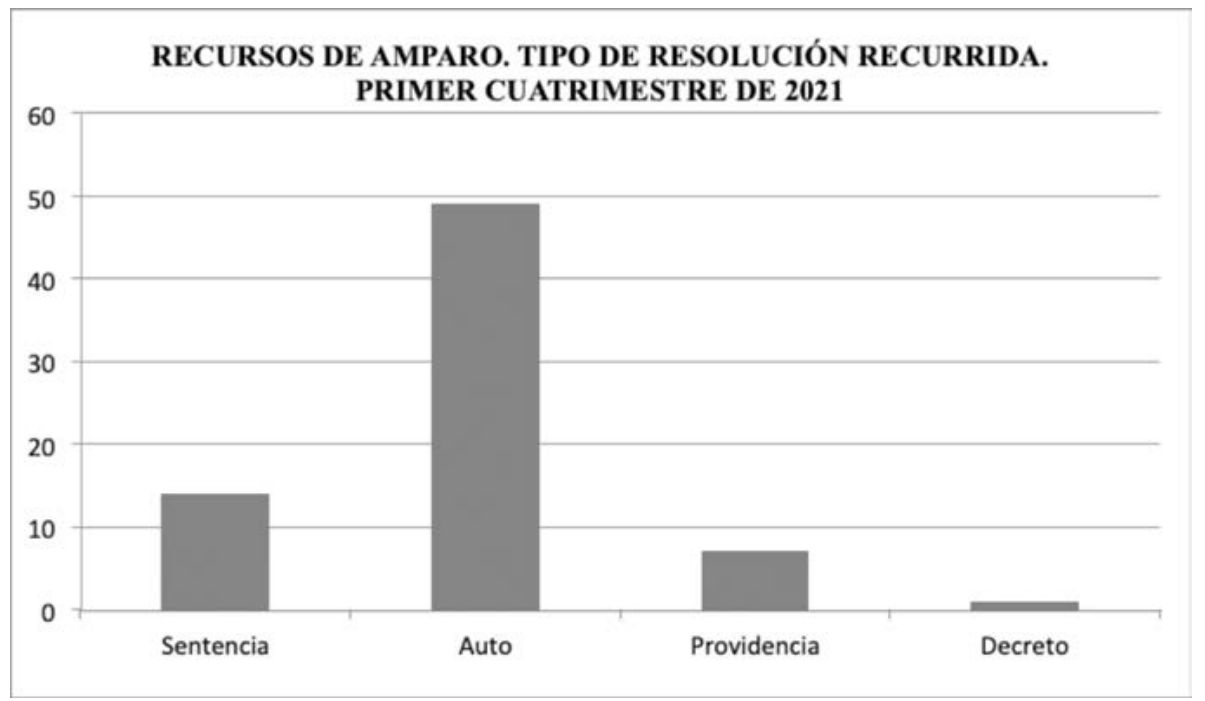

